\title{
The first German map of georeferenced ixodid tick locations
}

\author{
Franz Rubel ${ }^{1 *}$, Katharina Brugger ${ }^{1}$, Masyar Monazahian ${ }^{2}$, Birgit Habedank $^{3}$, Hans Dautel $^{4}$, Sandra Leverenz ${ }^{4}$ \\ and Olaf Kahl ${ }^{4}$
}

\begin{abstract}
Background: Georeferenced locations of ixodid ticks are required to depict the observed distribution of species. Further, they are used as input data for species distribution models also known as niche models. The latter were applied to describe current and future (projected) tick distributions. Beside model assumptions and selected climate parameters, the number of georeferenced tick locations available as a digital dataset is of fundamental importance for the reliability of such models. For Germany, however, no comprehensive dataset of ixodid tick species exists. The goal of this study was to put together all the available information on ixodid tick locations in Germany to produce such a digital dataset and to visualize it in a map.

Findings: A total of 2,044 georeferenced locations of ixodid ticks in Germany were compiled from two existing datasets (altogether 993 locations) and an extensive literature study (1,051 locations). The resulting digital dataset comprises the following tick species: Ixodes ricinus (1,855 locations), Ixodes apronophorus (1), Ixodes frontalis (1), Ixodes hexagonus (1), Ixodes trianguliceps (4), Dermacentor marginatus (77), Dermacentor reticulatus (96), Haemaphysalis concinna (8) and Hyalomma marginatum (1). The data were used to draw a tick map for Germany, showing I. ricinus occurring in the whole federal territory, while D. marginatus has been restricted to the climatically favoured region of the Rhine valley. Clustered locations of $D$. reticulatus were also documented in the Rhine valley as well as in Berlin and its vicinity.

Conclusions: The introduced map depicts for the first time the available geographical coordinates of ixodid tick locations in Germany. The digital dataset used to draw the map is provided to the scientific community as a basis for further investigations such as species distribution modelling.
\end{abstract}

Keywords: Ixodid ticks, Ixodes, Dermacentor, Haemaphysalis, Hyalomma, Distribution map, Dataset

\section{Background}

Tick species distribution changes according to climate, land use patterns and forest management [1]. Therefore, it is of particular interest to develop scenarios on future distributions of ticks and tick-borne diseases based on climate models and the available knowledge of tick ecology and physiology. Among other methods, species distribution models reconstructing the climatic niche were applied. They describe the potential distribution of a given species, which may be projected into the future by using climate model predictions. For example, the current and future distribution of Ixodes ricinus in Europe was

\footnotetext{
* Correspondence: franz.rubel@vetmeduni.ac.at

${ }^{1}$ Institute for Veterinary Public Health, University of Veterinary Medicine

Vienna, Veterinärplatz 1, A-1210 Vienna, Austria

Full list of author information is available at the end of the article
}

investigated [2], using the geographical coordinates of I. ricinus locations from another study [3]. Beside model assumptions and selected climate parameters, the number of georeferenced tick locations available as a digital dataset is of fundamental importance for the reliability of modelling results. They comprise distributions of tick species as well as the distribution patterns of tick-borne diseases such as tick-borne encephalitis, Lyme borreliosis [4], babesiosis [5,6], rickettsiosis [7] and others [8].

Digital datasets covering Europe were provided by Estrada-Peña et al. [3] and GBIF, the Global Biodiversity Information Facility [9]. Both datasets feature major data gaps especially for Germany. The same is true for Belgium, where a recently published study on the distribution of ixodid tick species [10] is not included in those two datasets so far. The provision of exact geographical 
coordinates of all the described locations of ticks and tick-borne pathogens should be standard in all modern papers. Georeferences may be included in digital datasets and used in subsequent studies, especially in those investigating the spatio-temporal distributions of ticks on a continental scale. For Germany, however, such comprehensive data as presented for Belgium [10] are missing so far. To reduce these shortcomings a literature study on georeferenced tick locations was performed. Results comprise of coordinates extracted from recent papers, extracted from restricted papers mainly published in German language, digitized from historical hand-drawn maps and added from unpublished material, i.e. kindly provided by colleagues.

Digitized locations, of course, are of lower accuracy than locations described by geographical coordinates determined by GPS in the field. Thus, accuracy measures were given for all data referenced in Table 1. It is distinguished between high (h), medium (m), low (l) and unknown (u) accuracy. A high accuracy $( \pm 30 \mathrm{~m})$ was allocated to coordinates given in degrees, minutes and seconds or in decimal degrees with at least 4-5 relevant decimal places. A medium accuracy $( \pm 1 \mathrm{~km})$ was assumed for coordinates given in degrees and minutes or in decimal degrees with at least 2-3 relevant decimal places. A medium accuracy was also assumed for ticks collected from animals (e.g. deer, dogs) or humans and for coordinates digitized from local maps. Coordinates digitized from regional maps were classified as lowaccuracy data $( \pm 10 \mathrm{~km})$.

\section{Findings}

A total of 2,044 geographical coordinates for Ixodes, Dermacentor, Haemaphysalis and Hyalomma tick locations was included (Table 1) and depicted in a map (Figure 1). These coordinates include 1,855 I. ricinus locations, by far the most widespread and abundant ixodid tick species in Germany, occurring in the whole federal territory. A large number of georeferenced locations were taken from two already existing datasets. The first dataset, the free open access to biodiversity data collection of the Global Biodiversity Information Facility [9,12], lists 217 I. ricinus locations. The second dataset [3] comprises 776 I. ricinus locations. These datasets complement one another very well. Duplicates (exact matches) within and between the datasets were eliminated. Further, 661 I. ricinus locations were added from recent tick monitoring projects, 79 locations were extracted from the literature and 122 locations were digitized from a hand-drawn map [22]. Finally, 8 locations of rare Ixodes species were included, among them the first record of I. frontalis in Germany [24]. The number of findings of rare Ixodes species is low because in most tick monitoring programs they were not explicitly determined.
Table 1 Number of georeferenced ixodid tick sampling sites in Germany compiled in this study

\begin{tabular}{|c|c|c|c|}
\hline No. Sites & Species & Accuracy & References \\
\hline 661 & 1. ricinus & $\mathrm{h}$ & $\mathrm{MM}, \mathrm{OK}$ \\
\hline 1 & 1. ricinus & $\mathrm{h}$ & {$[4]$} \\
\hline 13 & I. ricinus & h & [11] \\
\hline 217 & I. ricinus & u & {$[9,12]$} \\
\hline 8 & I. ricinus & $\mathrm{h}$ & [13] \\
\hline 10 & 1. ricinus & $\mathrm{h}$ & [14] \\
\hline 776 & I. ricinus & u & [3] \\
\hline 6 & 1. ricinus & $\mathrm{h}$ & {$[15]$} \\
\hline 6 & 1. ricinus & $\mathrm{h}$ & {$[16,17]$} \\
\hline 20 & I. ricinus & $\mathrm{h}$ & [18] \\
\hline 9 & I. ricinus & $\mathrm{h}$ & [19] \\
\hline 5 & 1. ricinus & h & {$[20]$} \\
\hline 58 & 1. ricinus & 1 & {$[21]$} \\
\hline 64 & 1. ricinus & 1 & {$[22]$} \\
\hline 1 & I. ricinus & $\mathrm{m}$ & [23] \\
\hline 1 & I.apronophorus & $\mathrm{m}$ & [23] \\
\hline 1 & I. frontalis & $\mathrm{h}$ & {$[24]$} \\
\hline 1 & I. hexagonus & $\mathrm{h}$ & {$[4]$} \\
\hline 3 & I. trianguliceps & $\mathrm{h}$ & {$[16,17]$} \\
\hline 1 & I. trianguliceps & $\mathrm{m}$ & {$[23]$} \\
\hline 2 & D. marginatus & $\mathrm{h}$ & {$[25]$} \\
\hline 75 & D. marginatus & 1 & {$[26]$} \\
\hline 6 & D. reticulatus & $\mathrm{h}$ & $\mathrm{HD}, \mathrm{MM}$ \\
\hline 2 & D. reticulatus & $\mathrm{h}$ & {$[11]$} \\
\hline 4 & D. reticulatus & $\mathrm{h}$ & [13] \\
\hline 6 & D. reticulatus & $\mathrm{h}$ & {$[27]$} \\
\hline 10 & D. reticulatus & $\mathrm{m}$ & {$[28]$} \\
\hline 2 & D. reticulatus & h & {$[16,17]$} \\
\hline 28 & D. reticulatus & $\mathrm{h}$ & {$[7]$} \\
\hline 242 & D. reticulatus & $\mathrm{h}$ & {$[25]$} \\
\hline 2 & D. reticulatus & $\mathrm{m}$ & {$[5,6]$} \\
\hline 9 & D. reticulatus & 1 & [29] \\
\hline 2 & D. reticulatus & 1 & {$[22]$} \\
\hline 1 & D. reticulatus & 1 & [30] \\
\hline 3 & Ha. concinna & $\mathrm{h}$ & $\mathrm{HD}, \mathrm{MM}$ \\
\hline 1 & Ha. concinna & $\mathrm{h}$ & {$[4]$} \\
\hline 1 & Ha. concinna & $\mathrm{h}$ & [13] \\
\hline 3 & Ha. concinna & 1 & {$[22]$} \\
\hline 1 & Hy. marginatum & $\mathrm{h}$ & [31] \\
\hline 2,044 & Total & & \\
\hline
\end{tabular}

Sampling sites not referenced were contributed by the authors MM (639 sites in Lower Saxony), HD and OK (31 sites in Berlin and in the federal state of Brandenburg). 


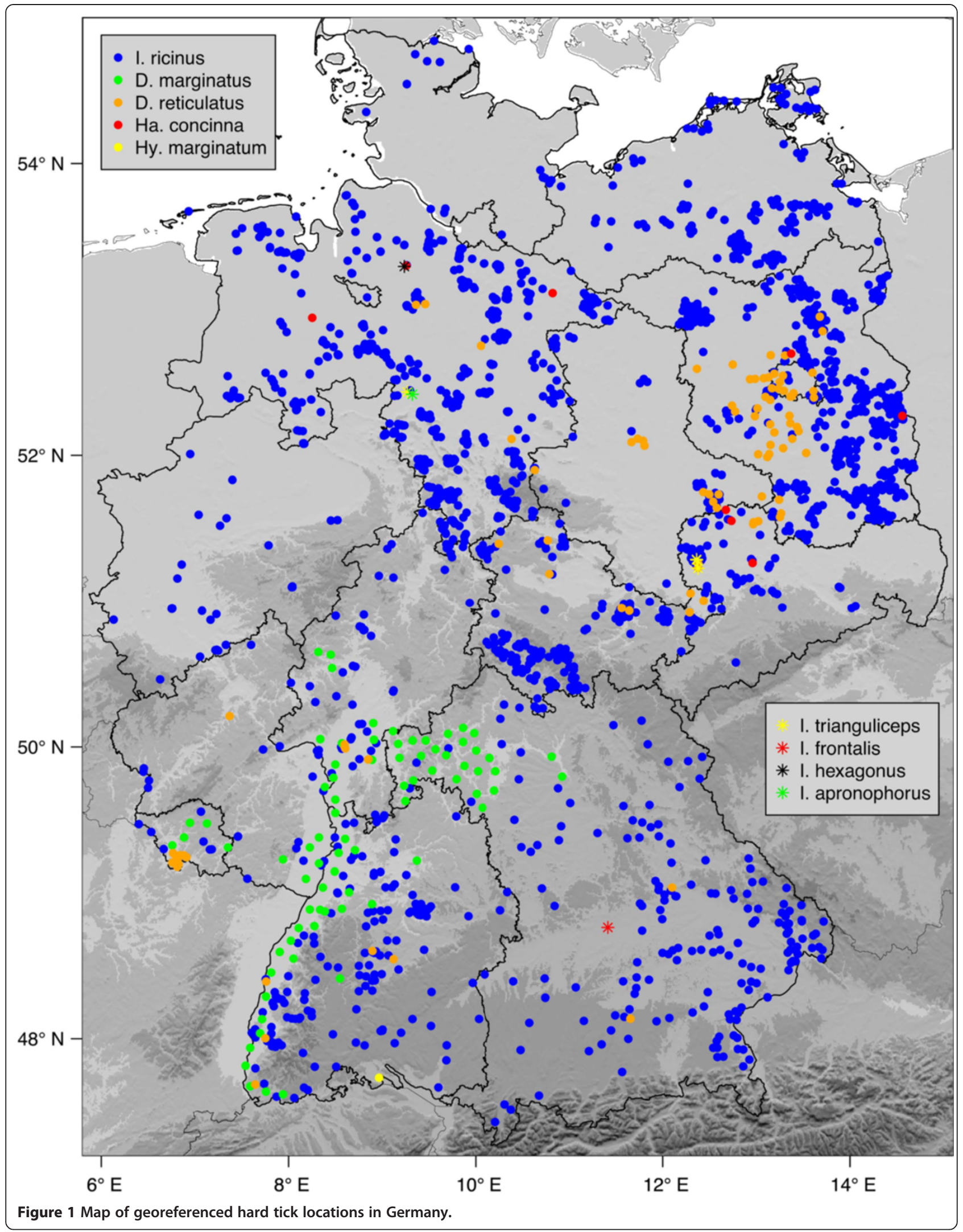


Two further at least regionally abundant tick species in Germany are Dermacentor marginatus and Dermacentor reticulatus. For D. marginatus, however, only two locations specified by geographical coordinates were provided [25]. Therefore, a historical hand-drawn map [26] was digitized to depict the well-known sources in the Rhine Valley. The latter is characterized by a warmer and dryer climate than usually found in Germany. It may be described as an extension of the Mediterranean climate to the north, a suitable habitat for the more thermophilic $D$. marginatus. The locations of $D$. marginatus were confirmed in 1990 by two of the authors, O. Kahl and $\mathrm{H}$. Dautel, who found high numbers of $D$. marginatus in the region of Hammelburg $\left(50.1^{\circ} \mathrm{N}, 9.9^{\circ} \mathrm{O}\right)$, unfortunately without documenting coordinates of the sampling sites. $D$. reticulatus, in Germany known as the marsh tick, was found in various habitats such as wastelands and meadows in many parts of Germany, except for most parts of northern Germany. It is particularly widespread and common in the federal states of Brandenburg and Berlin [7,25]. Further locations cluster in the Rhine Valley [25] and in the Saarland [28].

Additionally, 8 georeferenced locations of the relict tick Haemaphysalis concinna and 1 location of Hyalomma marginatum, the first report of an adult individual of that species in Germany [31], were included in the data collection. Further ixodid tick species listed for the fauna of Germany comprise Ixodes arboricola, I. canisuga, I. lividus, I. uriae, I. vespertilionis and Haemaphysalis punctata [8]. No georeferenced data were available for these species.

\section{Conclusions}

A new map of ixodid tick distributions in Germany is presented. The map was exclusively compiled from georeferenced locations, which are provided to the scientific community via a digital dataset (see Additional file 1). The most abundant species are $I$. ricinus, $D$. marginatus and $D$. reticulatus. The first record of a questing adult Hy. marginatum, a tick frequently transported by migratory birds into Germany as a larva or nymph [32], is noteworthy [31]. This unfed female of Hy. marginatum was found on the leg of an ornithologist living in the vicinity of Lake Constance, a well-known resting place for migratory birds at the German-Swiss border. Note that this finding of Hy. marginatum in Germany is not an isolated case. A second adult individual was found in the neighbouring Switzerland [3].

The brown dog tick Rhipicephalus sanguineus, a species complex endemic in the Mediterranean and other warm areas worldwide, was not considered here, although it is frequently introduced to Germany by traveling dogs. Various studies on $R$. sanguineus in Germany are available. For example, 60 tick-infested dogs, 17 of which had never left Germany, were investigated [33].
The study confirmed 16 small endemic foci in private homes and animal shelters. Nevertheless, no outdoor locations of $R$. sanguineus have been documented in Germany and in other central or north European countries so far [34].

We know that there are many more non-georeferenced ixodid tick sites described in Germany in the literature and also more ixodid tick species than listed in this study $[8,35]$. It is an ongoing project to fill our tick map with old and new georeferenced data to make it even more useful. To document the existing knowledge about past and current tick distributions is an important basis to project current potential distributions and to model future distributions especially of prominent vector tick species.

\section{Additional file}

Additional file 1: Georeferenced locations of ixodid ticks. Digital data compiled for this study comprising geographical longitude, latitude, species, accuracy and source.

\section{Competing interests}

The authors declare that they have no competing interests.

\section{Authors' contributions}

The study was designed by FR, the data collected and analyzed by FR, SL, BH and $\mathrm{KB}$, the map compiled by $\mathrm{KB}$ and the paper written by FR and OK. MM, $\mathrm{BH}, \mathrm{OK}$ and $\mathrm{HD}$ placed their own data. All authors read and approved the final version of the manuscript.

\section{Acknowledgements}

We are grateful to Peter Hagedorn, Martin Pfeffer, Kurt Pfister, Michaela Schulz and Jochen Süss for providing information on their tick sampling sites. The study was performed on behalf of the Federal Environment Agency within the UFOPLAN (FKZ 371348 402) and financed by the Federal Ministry for the Environment, Nature Conservation, Building and Nuclear Safety. Digital data will be archived, supplemented and provided by the Federal Environment Agency.

\section{Author details}

'Institute for Veterinary Public Health, University of Veterinary Medicine Vienna, Veterinärplatz 1, A-1210 Vienna, Austria. ${ }^{2}$ Governmental Institute of Public Health of Lower Saxony, Hannover, Germany. ${ }^{3}$ Section IV 1.4 - Public Health Pest and their Control, Federal Environment Agency, Berlin, Germany. ${ }^{4}$ tick-radar $\mathrm{GmbH}$, Berlin, Germany.

Received: 21 August 2014 Accepted: 4 October 2014 Published online: 10 October 2014

\section{References}

1. Medlock JM, Hansford KM, Bormane A, Co-authors: Driving forces for changes in geographical distribution of Ixodes ricinus ticks in Europe. Parasit Vectors 2013, 6:1.

2. Porretta D, Mastrantonio V, Amendolia S, Gaiarsa S, Epis S, Genchi C, Bandi C, Otranto D, Urbanelli S: Effects of global changes on the climatic niche of the tick Ixodes ricinus inferred by species distribution modelling. Parasit Vectors 2013, 6:217.

3. Estrada-Peña A, Farkas R, Jaenson TGT, Koenen F, Madder M, Pascucci I, Salman M, Tarrés-Call J, Jongejan F: Association of environmental traits with the geographic ranges of ticks (Acari: Ixodidae) of medical and veterinary importance in the western Palearctic. A digital data set. Exp Appl Acaro 2013, 59:351-366.

4. Faulde MK, Rutenfranz M, Hepke J, Rogge M, Görner A, Keth A: Human tick infestation pattern, tick-bite rate, and associated Borrelia burgdorferi s.l. infection risk during occupational tick exposure at the Seedorf military 
training area, northwestern Germany. Ticks and Tick-borne Dis 2014, 5:594-599.

5. Zahler M, Loster F, Merkle C, Rinder H, Gothe R: Risk of infection for dogs in Regensburg - A new endemic focus for Babesia canis and Dermacentor reticulatus in Germany (in German). Tierarztl Prax 2000, 28:395-398.

6. Zahler M, Steffenz T, Lutz S, Hähnel W, Rinder H, Gothe R: Babesia canis and Dermacentor reticulatus in Munich - A new endemic focus in Germany (in German). Tierarztl Prax 2000, 28:116-120.

7. Dautel H, Dippel C, Oehme R, Hartelt K, Schettler E: Evidence for an increased geographical distribution of Dermacentor reticulatus in Germany and detection of Rickettsia sp. RpA4. Int J Med Microbio/ 2006, 296(S1):149-156.

8. Petney TN, Pfäffle MP, Skuballa JD: An annotated checklist of the ticks (Acari: Ixodida) of Germany. System Appl Acarol 2012, 17:115-170.

9. GBIF: Global Biodiversity Information Facility. 2014, [Free and open access to biodiversity data, available at http://www.gbif.org, accessed 30 Jul 2014].

10. Obsomer V, Wirtgen M, Linden A, Claerebout E, Heyman P, Heylen D, Madder M, Maris J, Lebrun M, Tack W, Lempereur L, Hance T, Van Impe G: Spatial disaggregation of tick occurrence and ecology at a local scale as a preliminary step for spatial surveillance of tick-borne diseases: general framework and health implications in Belgium. Parasit Vectors 2013, 6:190.

11. Schulz M, Mahling M, Pfister K: Abundance and seasonal activity of questing Ixodes ricinus ticks in their natural habitats in southern Germany in 2011. J Vector Ecol 2014, 39:56-65.

12. Edwards $J$, Lane MA, Nielsen E: Interoperability of biodiversity databases: biodiversity information on every desktop. Science 2000, 289:2312-2314.

13. Hagedorn P: Untersuchung von Zecken als Marker für die Gefährdung Durch von Ihnen Übertragene Krankheiten; 2013 [Doctoral thesis, University Berlin, 129pp].

14. Tappe J, Strube C: Anaplasma phagocytophilum and rickettsia spp. Infections in hard ticks (ixodes ricinus) in the city of Hanover (Germany): revisited. Ticks and Tick-borne Dis 2013, 4:432-438.

15. Overzier E, Pfister K, Thiel C, Herb I, Mahling M, Silaghi C: Anaplasma phagocytophilum in questing Ixodes ricinus ticks: Comparison of prevalences and partial 16S rRNA gene variants in urban, pasture, and natural habitats. Appl Environm Microbiol 2013, 79:1730-1734.

16. Silaghi C, Woll D, Hamel D, Pfister K, Mahling M, Pfeffer M: Babesia spp. and Anaplasma phagocy tophilum in questing ticks, ticks parasitizing rodents and the parasitized rodents - Analyzing the host-pathogen-vector interface in a metropolitan area. Parasit Vectors 2012, 5:191.

17. Pfeffer M: Personal Communication on Ticks Collected in the Environs of Leipzig, Germany; 2014.

18. Vögerl MB: Zecken und Zecken-Übertragene Infektionskrankheiten in Niederbayern und der Oberpfalz; 2013 [Doctoral thesis, University of Munich, 120pp].

19. Bingsohn L, Beckert A, Zehner R, Kuch U, Oehme R, Kraiczy P, Amendt J: Prevalences of tick-borne encephalitis virus and Borrelia burgdorferi sensu lato in Ixodes ricinus populations of the Rhine-Main region, Germany. Ticks and Tick-borne Dis 2013, 4:207-213.

20. Schwarz A, Maier WA, Kistemann T, Kampen $\mathrm{H}$ : Analysis of the distribution of the tick Ixodes ricinus L. (Acari:Ixodidae) in a nature reserve of western Germany using Geographic Information Systems. Int J Hyg Environ Health 2009, 212:87-96.

21. Gupta SK, Schönberg A, Hiepe T: Prevalence of ticks in relation to their role as vector of Borrelia burgdorferi under autochthone conditions. Appl Parasitol 1995, 36:97-106.

22. Bauch R: Ixodes ricinus, Haemaphysalis concinna und Dermacentor reticulatus (Ixodida, Ixodidae) im DDR-Bezirk Leipzig. Angew Parasitol 1990, 31:57-64.

23. Walter G: Untersuchungen zur Zeckenfauna der Kleinsäuger des Naturschutzgebietes Hagenburger Moor. Beitr Naturk Niedersachsen 1980 33:99-103.

24. Schorn S, Schöl H, Pfister K, Silaghi C: First record of Ixodes frontalis collected by flagging in Germany. Ticks and Tick-borne Dis 2011, 2:228-230.

25. Menn B: Untersuchungen zur Verbreitung und Ökologie von Dermacentor Spec. (Ixodidae, Acari) in Deutschland; 2006 [Diploma thesis, University of Bonn, Germany].

26. Liebisch A, Rahman MS: Zum Vorkommen und zur vektoriellen Bedeutung der Zecken Dermacentor marginatus (Sulzer, 1776) und Dermacentor reticulatus (Fabricius, 1794) in Deutschland. Tropenmed Parasito/ 1976, 27:393-404.

27. Meyer-Kayser E: Dynamik des Zeckenbefalls bei Füchsen in Thüringen; 2013 [Doctoral thesis, University of Munich, 73pp].

28. Beelitz P, Schumacher S, Marholdt F, Pfister K, Silaghi C: Studie on the prevalence of Babesia canis canis in marsh ticks (Dermacentor reticulatus) in the Saarland (in German). Berl Munch Tierarztl Wochenschr 2012, 125:168-171.

29. Cornely M, Schultz U: Zur Zeckenfauna Ostdeutschlands. Angew Parasitol 1992, 33:173-183.

30. Immler R, Aeschlimann A, Büttiker W, Diehl PA, Eichenberger G, Weiss N: Über das Vorkommen von Dermacentor-Zecken (Ixodoidea) in der Schweiz. Bull Soc Entomol Suisse 1970, 43:99-110.

31. Kampen H, Poltz W, Hartelt K, Wölfel R, Faulde M: Detection of a questing Hyalomma marginatum marginatum adult female (Acari, Ixodidae) in southern Germany. Exp Appl Acarol 2007, 43:227-231.

32. Capek M, Literak I, Kocianova E, Sychra O, Najer T, Trnka A, Kverek P: Ticks of the Hyalomma marginatum complex transported by migratory birds into Central Europe. Ticks and Tick-borne Dis 2014, 5:489-493.

33. Gothe R: Rhipicephalus sanguineus (Ixodidae): Frequency of infestation and ehrlichial infections transmitted by this tick species in dogs in Germany; an epidemiological study and consideration (in German). Wien Tierärztl Mschr 1999, 86:49-56.

34. Gray J, Dantas-Torres F, Estrada-Peña A, Levin M: Systematics and ecology of the brown dog tick, Rhipicephalus sanguineus. Ticks and Tick-borne Dis 2013, 4:171-180

35. Kolonin GV: Fauna of Ixodid Ticks of the World (Acari, Ixodidae). 2009, [Online publication available at http://www.kolonin.org]

doi:10.1186/s13071-014-0477-7

Cite this article as: Rubel et al:: The first German map of georeferenced ixodid tick locations. Parasites \& Vectors 2014 7:477.

\section{Submit your next manuscript to BioMed Central and take full advantage of:}

- Convenient online submission

- Thorough peer review

- No space constraints or color figure charges

- Immediate publication on acceptance

- Inclusion in PubMed, CAS, Scopus and Google Scholar

- Research which is freely available for redistribution 